\title{
Analyzing the Effect of Exposure to a First-person Narrative of a Death Row Inmate on the Support of Capital Punishment
}

Kevin Omar Rodriguez ${ }^{*}$

Department of Psychology, Lake University, USA

*Corresponding author: Kevin Omar Rodriguez, B.A in psychology, pre-counseling and research, USA, Tel: 915 790 7786; E-mail: kevinomarrodriguez95@gmail.com

Received date: June 13, 2017; Accepted date: June 22, 2017; Published date: June 29, 2017

Copyright: (c) 2017 Rodriguez KO, et al. This is an open-access article distributed under the terms of the Creative Commons Attribution License, which permits unrestricted use, distribution, and reproduction in any medium, provided the original author and source are credited.

\begin{abstract}
This experiment tests whether the method of presentation of a story of a death row inmate affects the degree of support toward capital punishment in a sample of undergraduate students and staff. The independent variable was whether participants were presented with the story of a person on death row told from that person's point of view or same story about the inmate presented by his brother. Thus the intervention methods in the study included students introduced to first-person information and third-person information. The dependent variable was the degree of support toward the death penalty, measured both before and after exposure to the story. The sample consisted of 100 undergraduate students and staff from OLLU that were randomly assigned to the point of view of the story. It was hypothesized that the students exposed to first-person information (the inmate's story) would demonstrate more of a decrease of support toward capital punishment (CP) than those students exposed to third-person information (his brother's story) because the participants may feel more empathetic and be more likely to forgive the inmate after hearing the story from his point of view. Results were consistent with the hypothesis: participants exposed to the story from the inmate decreased in CP endorsement and those who were told the story from his brother slightly increased in CP endorsement. This finding may suggest that our belief system regarding CP can be influenced by the type of information presented to us.
\end{abstract}

Keywords: Capital punishment; Death penalty; Forensic psychology; First-person; Third-person; Death row; Contextual influences; Legal system; Convict; Change in endorsement

\section{Introduction}

\section{Analyzing the effects of first-person information toward the support of capital punishment}

The death penalty has caused huge controversy throughout the course of history in the United States Mandery [1]. The idea of implementing this form of what can be considered punishment for the victim or remedy for society varies significantly among different populations within the United States. There are several variables that affect an individual's degree of support toward the death penalty. The purpose of the present study is to evaluate two different forms of narrative (first and third-person) presented to a sample of university students and staff regarding the topic of the death penalty. Consequently, it could be beneficial to note a significant change in their degree of support toward a capital punishment between the types of information.

\section{Executing the innocent}

The continued practice of execution as a form of punishment reflects the moral values of not only the individuals that deliberately demand this practice but also of the states that allow this form of punishment Clarke \& Whitt [2]. Currently, the criminal justice system is less than perfect. Erroneous convictions have been made that resulted in executing innocent people. In fact, it is estimated that errors have been made in the convictions of one in nine persons put on death-sentences in the United States Clarke \&Whitt [2]. For example,
Joseph Roger O'Dell who was accused a convicted for the murder of Helen Schartner was executed on July of 1997. Upon his execution, there was a mismatch on the analysis of blood evidence (Hsu). Given the fallibility of the legal system, use of the death penalty and its moral status in the United States can thus be questioned.

One of the biggest fears that an individual could possibly face is being sentenced to capital punishment for a crime that was either wrongly condemned or blown out of proportion and such consequences should not be implemented McCarthy [3] describes in an article the immeasurable feeling of despair from an individual when acknowledging the possible execution. The context of the article provides a first-person example of the intensity of despair that could occur when being confronted with flaws of the justice system. For background information, the article narrates the story about Joseph Brown, an individual that was charged with homicide and rape charges and consequently, experienced 14 years in Florida's death row. Brown was found innocent 15 hours before his execution. According to the article, there is an error rate of about 14 per cent of individuals on death row McCarthy [3].

\section{Capital punishment endorsement in the United States}

Support of capital punishment in the United States has been significantly decreasing over time (Death Penalty Information Center). The latest national poll regarding the death penalty was produced by Langer Research Associated and was conducted on October of 2014. The poll demonstrates that $52 \%$ of Americans prefer life without parole rather than capital punishment (Langer Research Associated). With this in mind, it becomes a subject of interest to analyze the different components that can influence a particular individual to have a shift in their view. 


\section{Factors Associated with Capital Punishment Endorsement}

\section{Perceived psychopathy of the criminal}

An important aspect that could influence the degree of support toward capital punishment is the amount of background information given from a particular individual sentenced to the death penalty. According to Cox, Clark, Edens, Smith, \& Magyar [4], a powerful predictor of whether a person will demonstrate support toward the execution of an individual is how psychopathic they perceive the criminal to be, and thus a potential threat to society.

When an individual on death row is perceived as having traits that represent psychopathy, it is more likely that the perceiver will demonstrate a higher degree of support toward the death penalty in general (Cox et al.) [4].

The psychopathic traits correlate with personality traits. For example, remorselessness, grandiosity, and callousness create the perception that the individual sentenced to death is likely to commit acts of violence while incarcerated if given a life without parole sanction (Cox et al.) [4]. Evens, Colwell, Desforges, and Fernandez [5], found that more undergraduates were in favor of capital punishment when the sentenced individual was identified as having psychopathic traits $(60 \%)$ in comparison to psychotic traits $(30 \%)$, or when the prisoner did not have a mental disorder (38\%). The study also suggested that more support for the death sentence is present among students when the psychotic numerical rating of the incarcerated scored higher from the Psychopathy Checklist-Revised.

\section{Religious affiliation of perceiver}

Another variable that has an impact on an individual's capital punishment support endorsement level is religious affiliation. According to James, John, and Francis [6], the ethical component of being committed to monotheism, the belief of one loving God, predicts higher degree of rejection toward the death penalty. Past literature also distinguishes the shift in support of capital punishment between past and present (Akin). In recent times, religious individuals have been less supportive of the death penalty (Brugger).

\section{Race of perceiver}

Another significant factor that can play a major role on one's degree of support toward capital punishment is belonging to a specific racial or ethnic group. According to Gregory and Stacy, the different demographics present have different ranges of support towards CP. The research implied on this article broadens the perception of such a delicate topic by acknowledging patterns and a variety of reasons of why a group of individuals may have a strong support toward the death penalty or completely reject the system. A study conducted in 2015 by Pew Reseach Center indicates that $63 \%$ of White Americans, 34\% of Black Americans, and of $45 \%$ Hispanics are in favor of the death penalty. Another element of the article that expands the perception is that the article does not only discuss the numerical value of different social groups and their degree of support toward capital punishment, but it attempts to asses which factors can lead to a change in opinion.

\section{Exposure to issues surrounding capital punishment}

According to Michael \& Cochran [7], the reason why many individuals considered themselves supportive of capital punishment is that they are unaware of the underlying issues regarding the death penalty. This ideology is known as the Marshall Hypothesis. If presented with sound information about the death penalty, it is expected that many of the supporters would reduce their degree of support. On the other hand, there are individuals that base their strong level of support toward capital punishment on past experiences and personal connections, which create an emotional attachment thus making it significantly more difficult to decrease their degree of support Michael \& Cochran [7]. The practice of the death penalty is one of the most debatable and prevailing issues of this era. In order to properly comprehend the underlying issues around capital punishment, it is necessary to acknowledge the different components that influence both a positive and negative support toward the death penalty [8].

The accumulative literature demonstrates how the most abstract influences such as religious affiliations and emotional attachments have a significant effect on the way an individual views the death penalty [9]. In terms of the present research, it was expected that students exposed to an inmate who is sentenced to death telling the story of his case (first-person information) will cause participants to develop an emotional connection with the individual on death row and therefore revaluate their degree of endorsement of capital punishment by acknowledging a disagreement between their mind and heart [9-11].

\section{The roles of prosocial behavior and forgiveness}

In order for a society to properly function, the individuals' actions are guided by prosocial behavior, also known as helping behavior. Prosocial behavior is the concept that members of society must attempt to help each other, thus building relationships [12]. Part of prosocial behavior includes obeying rules and conforming to norms [13]. When it comes to capital punishment endorsement, it is important to acknowledge that some individuals believe that a person should be executed if his/her execution will ultimately benefit society, and would thus be a prosocial act.

Attitude change regarding capital punishment endorsement may, therefore, be more likely to occur if a person comes to understand that the death penalty does not benefit society and that forgiveness should be implemented to the individual by applying a less severe sentence such as life without parole.

Furthermore, when an individual learns of the personal story of a convict who has been sentenced to death and their case from their perspective, they may be more likely to feel that the death penalty is not in the best interest of society and thus is not a prosocial act. This may be enhanced when the perceiver feels empathetic feelings or has thoughts of forgiveness toward the inmate. Forgiveness is more likely to occur when an individual created a minor offense or when the perpetrator apologizes (Exline, Worthington, Hill, McCulloiugh). Therefore, it is implied that when a death row inmate personally apologizes, those around her/him may feel more sympathetic and forgiving 


\section{Purpose of Study}

\section{Research hypothesis}

Does the presentation of the story of a death row inmate, from the inmate's point of view, decrease the degree of support toward capital punishment more than does presentation of the story from a thirdperson point of view?

\section{Variables in the present study}

The independent variable in the study is the point of view of the person telling the story of the case of a murder. The case was either described by the criminal or by the criminal's brother. The dependent variable was changed in the degree of support toward the death penalty and empathy towards the specific case. Extraneous variables that may have an influence in the study include religious affiliations, personal connection, family values, social desirability, extremes beliefs of the issue, and over-sensitive personalities.

The first mentioned extraneous variable is religious affiliation and can have a significant effect on a given response because if the participants' life is strictly influenced by religious beliefs, this can stop any alteration in their belief system. The second extraneous variable in the study is personal connection. Past experiences regarding capital punishment can create an emotional bias in the participants' response.

The third extraneous variable is if the individual has ingrained family values that affect their perception of delicate social issues. The fourth extraneous variable in the study is social desirability bias. Individuals in the study may want to be perceived as benevolent and consequently, may pick to disagree in order to fit societal expectations. The fifth extraneous variable is extreme belief on either acceptance or rejection of capital punishment. Participants who fall in either of the extremes may be difficult to have a change in support. The sixth extraneous variable mentioned in the study is over-sensitive personalities. Students who are emotionally fragile and get heavily impressed may decide to discontinue participation. For these personalities, experiential and cognitive variables will be controlled by random assignment of participants to the point-of-view conditions.

\section{Method}

\section{Overview of design}

The study is a pretest-posttest, one independent variable, two-group design. Participants in the study were randomly assigned to one of the two groups (exposure to first-person or third-person inmate story). The purpose of the study was to test whether exposure to a story of a murder case from an inmate's point-of-view (first-person information) decreases the degree of support toward capital punishment compared to exposure to the story of the case (third-person information) in a sample of undergraduate students and staff.

\section{Participants}

The sample of the study included 100 undergraduate students and staff that were recruited from a Catholic institution of higher learning (Our Lady of the Lake University). The participants' ages ranged from 19 to 65 years old and the mean was 30.9 years $(S D=12.3)$. There were 81 female participants and 19 male participants. Most of the participants identified their ethnicity as Hispanic $(n=74)$. The rest of the participants identified themselves as either Caucasian $(n=10)$, Latino $(n=8)$, African American /Black $(n=4)$, or Mixed Race $(n=4)$. The majority of the participants classified themselves as other, which would indicate staff members $(n=36)$. The rest of the participants were undergraduate students $(n=27)$, senior $(n=19)$, junior $(n=13)$, and sophomores $(n=5)$. The researcher was aware of the possibility of a negative emotional response. If the participant appears negatively affected during any part of the experiment, the researcher will offer to escort them to counseling services which is located in Providence Hall. In all cases, the researcher will ask the participant if they are feeling stable at the end of the experiment and ask if they have any additional questions.

\section{Materials Used in the Present Study}

\section{Informed consent}

The investigator obtained written informed consent that included the appropriate information concerning the study, providing adequate opportunity for the subject to consider all options, responding to the subject's questions, ensuring that the subject has comprehended this information, obtaining the subject's voluntary agreement to participate and, continuing to provide information as the subject or situation requires

\section{Capital punishment attitude scale}

The pre and posttest included the capital punishment attitude scale developed by O'Neil, Patry and Penrod [8]. This scale measures the endorsement level towards capital punishment and includes subscales of general support, retribution and revenge, death penalty as a deterrent, death penalty is cheaper and life without parole. This scale was composed of 15 items that were rated on a scale that ranged from 1 (Strongly Disagree) to 6 (Strongly Agree). Request to utilize the scale was emailed to Marc Patry and he responded that the scale was in the public domain and can be utilized. The other scale of measurement was the Empathy toward Death Row Inmate Scale, which was created by the investigators, Kevin Rodriguez and Kathryn Anderson. This scale was composed of 10 items, rated on the same rating scale, and measured the empathy level towards the specific case that was presented to them. Both measures are included in the AppendixThe debriefing script explained that the narrative is fictitious, the purpose of why the narrative was fictitious and to ask if there are any questions or concerns as well as guidance to counseling services at OLLU if needed. Attempt to gather students by providing a very brief explanation and it will be done in favor mode.

\section{Procedures}

Participants were approached and invited to participate. They were then provided with the informed consent form under the format provided by the IRB. If they agreed to participate and sign the consent form, they were then given a demographic questionnaire, followed by the capital punishment attitude scale (pre-test).

They were then told the following, "I will now provide you w/a narrative of a man named Spencer. You will hear an audio recording of the narrative and I encourage you to follow along with this sheet."

They were then given a (fictitious) story about an inmate on death row who admits to committing a murder, which was provided in 
writing and also heard an audio recording of the inmate by headphones

The story was either provided in a first-person point of view from the perspective of the inmate, or by a third-person narrative that will include exactly the same story but from the inmate's brother. These narratives were created by the researchers and appear below.

After reading and hearing the story, participants were then asked to complete the Spencer's case rating scale and the capital punishment endorsement scale (post-test). The debriefing script was given after the participants answered both questioners. The debriefing script explained that the narrative was fictitious, the purpose of why the narrative was fictitious and to ask if there are any questions or concerns.

\section{First-person narrative}

The first-person information is the first group of the independent variable. The purpose of the first-person information was to provide a type of narrative that will reach the emotions of the participant. The first-person information was expected to create emotion thus consciousness on the students. First-person information will be exposed to the students by demonstrating a narrative that will discuss the story of a convict's experience on death row. The narrative included elements that will expose the human self of the incarcerated and soon to be executed individual. The narrative was played on a recorded message of the voice of an adult male friend of the researcher.

My name is Spencer. In 1995, I committed a crime of passion that resulted in the murder of an innocent victim. My girlfriend and I had been together for four years. Before that, I never thought I could love someone the same way I loved her. Unfortunately, I loved her so much that I could not control myself and my jealous behavior. Ultimately, my own insecurities resulted in her death; an event that causes me an immense amount of pain every day of my life here in jail.

As a consequence, for my crime of passion, I have been sentenced to death. Ever since my conviction, the thought of me dying in a near future terrifies me every day. I completely recognize my mistake and have apologized to the family members of the victim.

Although I am beginning to accept my fate, it is hard to acknowledge that soon I will cease to exist. I truly do enjoy being alive, every minute of it. I enjoy every sight, sound, and taste. I love life as much as I loved her. It is exhausting to imagine that I will be leaving behind many dreams, goals and ambitions. I will be leaving behind all of what she left behind.

\section{Third-person narrative}

The third-person narrative contained the same components as the first-person narrative but from a third-person perspective (that of the inmate's brother). The same man provided this recorded statement as in the first-person narrative condition.

In 1995, my brother Spencer committed a crime of passion that resulted in the murder of an innocent victim. His girlfriend and he had been together for four years. Before that, I never thought he could love someone the same way he loved her. Unfortunately, he loved her so much that he couldn't control himself and his jealous behaviour. Ultimately, his own insecurities resulted in her death; an event that causes him an immense amount of pain every day of his life in jail. As a consequence, for his crime of passion, he has been sentenced to death. Ever since his conviction, the thought of his death in a near future terrifies him every day. He completely recognizes his mistakes and has apologized to the family members of the victim. Although he is beginning to accept his fate, it is hard for him to acknowledge that soon he will cease to exist. He truly does enjoy being alive, every minute of it. He enjoys every sight, sound, and taste. He loves life as much as he loved her. It is exhausting for him to imagine that he will be leaving behind many dreams, goals, and ambitions. He will be leaving behind all of what she left behind.

\section{Debriefing script}

Participants were thanked for their participation. Then, they were told about the purpose of the study and disclosure about the fictitious nature of the narratives in order to obtain natural responses. The participants were also reminded about confidentiality and asked for any possible concerns or comments regarding the study. In order to maintain the validity of the study, we asked the participants not to discuss the experiment until the end of summer of 2016. The participants were also given the option to be escorted to the counseling services from Our Lady of the Lake University if needed.

\section{Resolution of possible ethical concerns}

In order to relieve an extreme stress reaction due to the narratives, the participants were reminded that they were able to discontinue participation. Informed consent was given at the beginning of the study by informing the participants of the nature of the experiment. The participants were notified that they have the ability to discontinue participation anytime during the study.

The participants were then notified about confidentiality and it was implemented throughout and after the study by being extremely protective of their identities. Debriefing was told at the end of the study by explaining the use of deception and letting the participants know about the other comparative group. In case one of the participants found out about the opposite group and desired to participate in the opposite control group, we were able to provide that same form of exposed information.

\section{Results}

\section{Data preparation}

After data was collected, frequency analyses were used on all variables in SPSS to ensure that data was entered properly. Three items on the Death Penalty Attitude Scale and four items of Spencer's Case Rating Scale were reversed scored (see Appendix for noted reverse scored items). Mean variables were created for all pretest CPE items, posttest CPE items, and Spencer's Case items. Pretest and posttest mean scores were also created for the General Support, Retribution and Revenge, Death Penalty as a Deterrent; Death Penalty is Cheaper and Life without the Opportunity of Parole (LWOP).

Tukey's Exploratory Data Analysis (EDA) was used to identify any outliers on Spencer's Case and Capital Punishment Endorsement (CPE), and subscale variables that could possibly skew the data. Far outliers were found only for the Death Penalty is Cheaper and LWOP Allows Parole subscales. Cranach's alpha coefficients were calculated for the total CPE scale and the index scale without the Death Penalty Is Cheaper and LWOP Allows Parole subscales. The index without these two scales was more internally consistent (pretest $=0.811$; posttest $=0.842$ ) than the total scale (pretest $=0.774$; posttest $=0.822$ ). 
Thus, the CPE index with only the general support, retribution as a revenge and death penalty as a deterrent subscales was used in subsequent analyses. Change (difference) scores were calculated by subtracting the posttest from the pretest scores for the CPE index. Descriptive statistics were conducted on gender, classification, age, and ethnicity in order to describe the participants.

\section{Tests of first and third person accounts on CPE}

Independent samples t-tests were conducted to assess the effects of the source of the presentation on capital punishment endorsement attitude change scores and endorsement of capital punishment and empathy specifically for Spencer's case. Consistent with the hypothesis, participants who heard and read the case narrative from Spencer (firstperson) slightly decreased in CPE by condition, which included the variables of general support, retribution and revenge, and death penalty as a deterrent $(M=-0.113 ; S D=0.389)$, and those who received the narrative from Spencer's brother (third-person) slightly increased in their CPE attitudes $(M=0.029 ; S D=0.299), t(98)=-2.05, p=0.043$. Figure 1 and 2illustrates this difference.

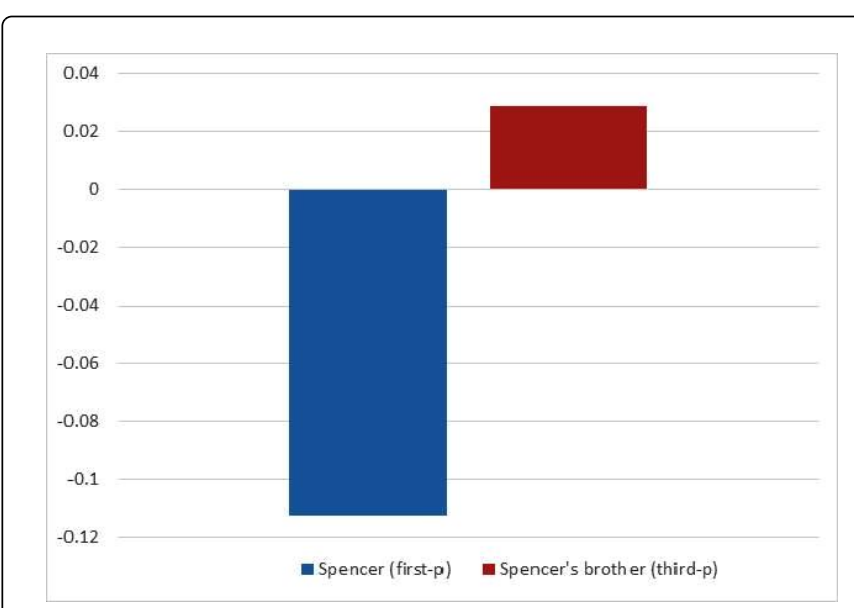

Figure 1: Capital punishment endorsement index difference score.

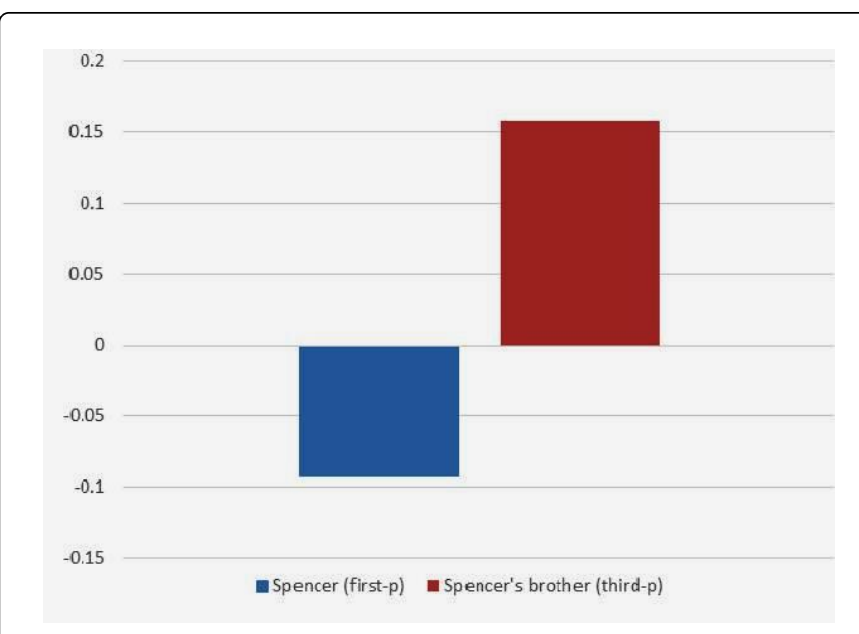

Figure 2: Change in general support for capital punishment by condition.
Participants also demonstrated a significant difference in their change in level of endorsement on the General Support subscale across the two conditions. The participants that were exposed to the firstperson narrative demonstrated a slight decrease in general support for $\mathrm{CPE}(\mathrm{M}=-0.092 ; \mathrm{SD}=0.538)$ and those participants that were introduced to the third-person narrative demonstrated an increase in their level of CPE on the General Support subscale $(M=0.157$; $\mathrm{SD}=0.580), \mathrm{t}(98)=-2.22, \mathrm{p}=0.029$.

\section{Demographic variables}

Tests for gender effects were not reliable due to the low number of men represented in the sample (19/100), thus were not conducted. Participant age and educational classification were correlated with the CPE index and subscales, as well as with the CPE endorsement regarding Spencer's case variable. Neither age nor classification were significantly related to any of the variables, all ps $>0.05$.

\section{Discussion}

Overall, the research findings support the hypothesis that those individuals that were exposed to the first-person narrative would demonstrate a decrease in CPE compared to those who were presented with a third-person narrative. Although degree of forgiveness toward the inmate was not directly measured, this may have occurred because the participants felt more forgiving [14].

The research findings also provide insight concerning how the participants that were exposed to the third-person narrative demonstrated an increase in CPE, thus were less forgiving of the incarcerated. Past literature has demonstrated that an individual is more forgiving when the perpetrator personally apologizes for his or her wrongdoing (Exline, Worthington, Hill, McCulloiugh). The narratives include a sentence that states how the perpetrator has apologized and regrets his crime [15]. It can be suggested that hearing that statement from the actual perpetrator instead of his brother created more sympathetic emotions within the participants, and thus a decrease in CPE.

\section{Limitations}

The most prominent limitation faced was uneven sample sizes of participants among conditions. More participants (53) received the third-person condition than those who were exposed to the firstperson condition (46). This was due to a format error by the research randomizer software. Because of the robust sample sizes and the normal distributions of the dependent variables, this difference did not cause unreliable results. Also, the Spencer's Case Rating Scales developed for this study did not directly measure empathy or feelings of forgiveness, therefore the explanation that those feelings may have affected the CPE ratings could not be tested.

\section{Future Research Directions}

If one analyzes the effect of first-person information in such a delicate topic, one can grasp an idea of the extent the introduction of first-person information can influence our attitudes. It will be important to measure relevant feelings (e.g., empathy and forgiveness) of the participants that may mediate the relation between the type of narrative and the attitude endorsement. Future research could also address more realistic decisions of jurors (or simulated jury situations) regarding capital punishment cases rather than general endorsement. 
Citation: Rodriguez KO (2017) Analyzing the Effect of Exposure to a First-person Narrative of a Death Row Inmate on the Support of Capital Punishment. J Foren Psy 2: 1000123. doi:10.4172/2475-319X.1000123

Page 6 of 6

Fruitful future research could also analyze the same effect of exposure but with different controversial social topics. For example, the same research process could be utilized when attempting to evaluate controversial topics that also pertain to the value of human life, for example, abortion or assisted suicide.

\section{Acknowledgement}

This project was completed in gratitude to the author's research mentor from Our Lady of the Lake University, Dr. Kathryn Anderson, and the McNair Scholars Research Program

\section{References}

1. Mandery EJ (n.d.) A wild justice The death and resurrection of capital punishment in America.

2. Clarke A, Whitt L (2013) State execution: A morally indefensible proposition. NLG Review 70: 248-252.

3. McCarthy C (2010) Death row survivor tells the real story. NCR 46: 6a.

4. Cox J, Clark JC, Edens JF, Smith ST, Magyar MS (2013) Jury panel member perceptions of interpersonal-affective traits of psychopathy predict support for execution in a capital murder trial simulation. Behav Sci Law 31: 411-428.

5. Edens JF, Colwell LH, Desforges DM, Fernandez K (2005) The impact of mental health evidence on support for capital punishment: Are defendants labeled psychopathic considered more deserving of death? Behav Sci Law 23: 603-625.

6. Unnever JD, Bartkowski JP, Cullen FT (2010) God imagery and opposition to abortion and capital punishment: A partial test of religious support for the consistent life ethic*. Sociol Relig 71: 307-322.

7. Michel C, Cochran JK (2011) The effects of information on change in death penalty support race and gender-specific extensions of the Marshall Hypotheses. J Ethn Crim Justice 9: 291-313.

8. Gudorf CE (2013) Christianity and opposition to the death penalty: Late modernshifts. Dialog: J Theo 52: 99-109.

9. Horowitz MJ, Wilner M, Alverez W (1979) Impact of Events Scale: A measure of subjective stress. Psychosom Med 41: 209-218.

10. Mallicoat SL, Brown GC (2008) The impact of race and ethnicity on student opinions ofcapital punishment. J Ethn Crim Justice.

11. National Polls and Studies (2015).

12. ONeil KM, Patry MW, Penrod SD (2004) Exploring the effects of attitudes toward the deathpenalty on capital sentencing verdicts. Psychol Public Policy Law 10: 443-470.

13. Shatz SF, Dalton T (2013) Challenging the death penalty with statesitics: Furman.

14. McCleskey a Single County Case Study. Card Law Rev 34: 1227-1282.

15. Students' Beliefs Vary by Gender and Politics (2004) America 191: 5-6. 